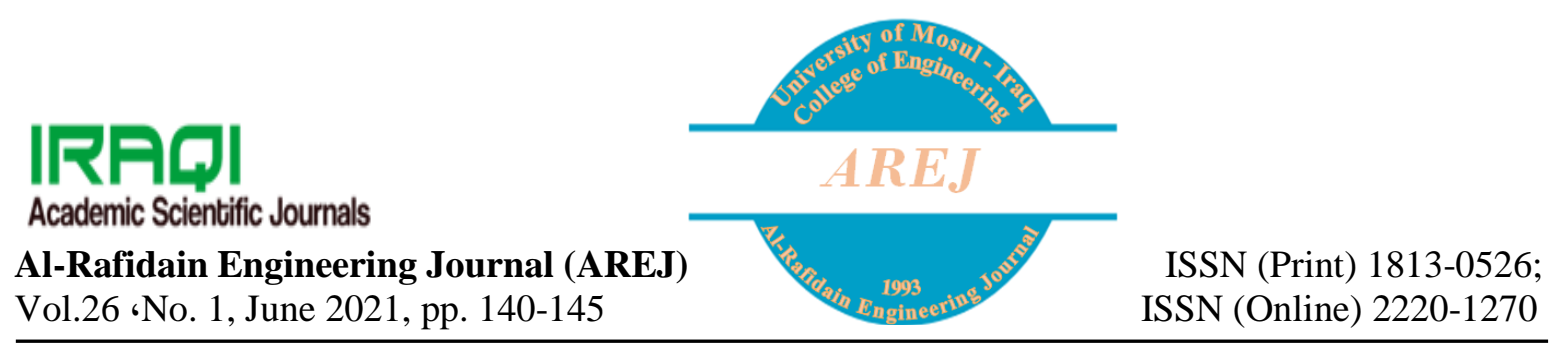

\title{
Handling the Error in Weighing Signal
}

\author{
Abdelkader Faris Abdelkader \\ abdlkaderfares52@gmail.com
}

Fakhrulddin Hamid Ali

fhazaa@uomosul.edu.iq

Computer Engineering Department, Collage of Engineering, University of Mosul

Received: 7/9/2020

Accepted: $1 / 11 / 2020$

\begin{abstract}
The paper presents and discusses how to use some software techniques to handle the error in the weighing signal that is produced from a load cell. The load cell is the best sensor used to transform the weight to an electrical signal. In industry the production of an accurate weighing signal suffers from a noisy environment. Different sources of noise like electromagnetic fields from machines, motors, microwaves and power lines in addition to tempreture variations and humidity have significant effects on weak electrical signals produced by load cells. The software filtering is adopted to reduce or remove the unwanted effects. The measured combined error is $\pm 0.416 \%$ when the load is $6000 \mathrm{~g}$. The error normal distribution has a sigma improvement equals to $6.922 \%$. With the adaptive hardware gain the measurement time is reduced by about $20 \%$.
\end{abstract}

Keywords: Arduino; Loadcell; Differential signal; Instrumentation Amplifier; ADC converter;

https://rengj.mosuljournals.com

Email: alrafidain_engjournal@umosul.edu.iq

\section{INTRODUCTION}

The weighing signal is used in many factories, such as cement, drug, asphalt, refineries as well as is used in some of control systems as shown in figure(1)[1]. Therefore, we need accuracy in weighing objects during manufacturing or packaging. So that, the load cell from strain gauge type is used since it has high accuracy[2] .

The load cell produces a very weak signal in millevolt. The ADC deals with the signal in volt, therefor, using of instrumentation amplifier is very necessary to enlarge the signal. The signal will contain some errors as a result of noise. For the purpose of error reduction in the weighing signal different approaches are implemented.

The main element of research is the reduction of error in the weighing signal. This error is dealt with using two parameters:
The average of many readings.

The second, sigma representing different readings around the average.

To achieve the goal, two objectives are implemented.

They are :

1- Windowing.

2- Adaptive gain.

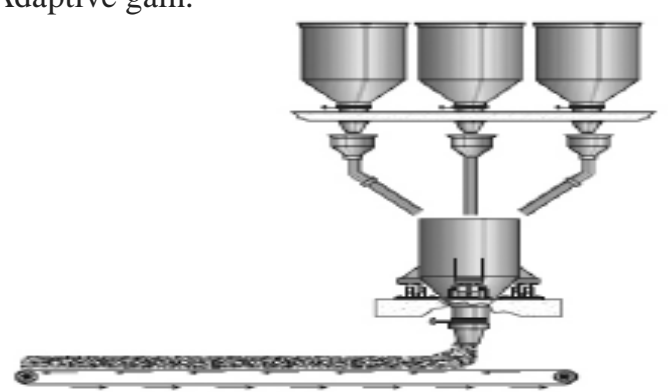

Figure(1). Asphalt factory [1].

\section{Previous Work}

Since the weighing signal that is produced from the Load cell suffers from the noise, the researchers started to suggest and presenting some ideas to remove the noise, and from a set of 
previous ideas, some suggestions and actions are reviewed.

Munyao Kitavi(2009) proposed approach to reduce the error in weighing signal by reducing the resolution from 10 bits for ADC to 8 bits in software [3].

Karunamoy Chatterjee, Sankar Narayan Mahato and Subrata Chattopadhyay(2012) proposed a compensation filter to handle the error in weighing signal. Because the filter will track the variation in the signal produced from load cell and smoothies it[4].

Kyoo Nam Choi (2017) presented approach consists of two stage. The first stage, is only one low pass filter with variable cut off frequency for rejecting peak noise components. The second, consists of six stage of low pass filter having Sallen key topology for obtaining bigger pulse width ratio [5].

Sunethra Pitawala(2019) solved the error in weigh signal during the products in motion by using 1-D kalman filter algorithm to estimate the optimal steady state of the time series data for the weight signal. Its construction is two parts, they are value prediction and next value prediction[6].

3.Proposed and implemented work

A block diagram of the proposal system is illustraited in figure(2).

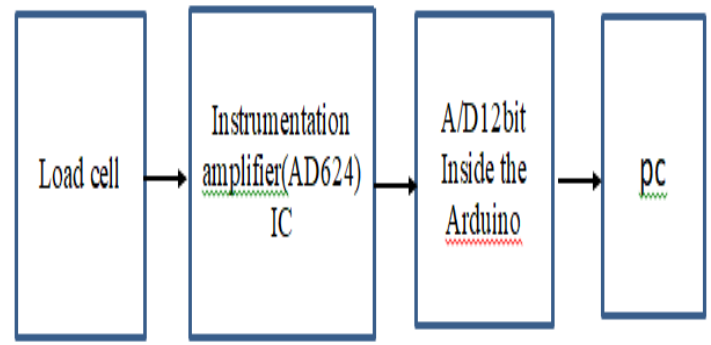

Figure(2). Block diagram of basic system.

First, the load cell has to be tested before it is used in the electronic weighing system if it is linear or not. By Appling range of loads from 1000g to 20000g and notice the output voltage from Load cell using accurate digital voltmeter of accuracy $(0.001 \mathrm{mv})$ as shown in figure(3).

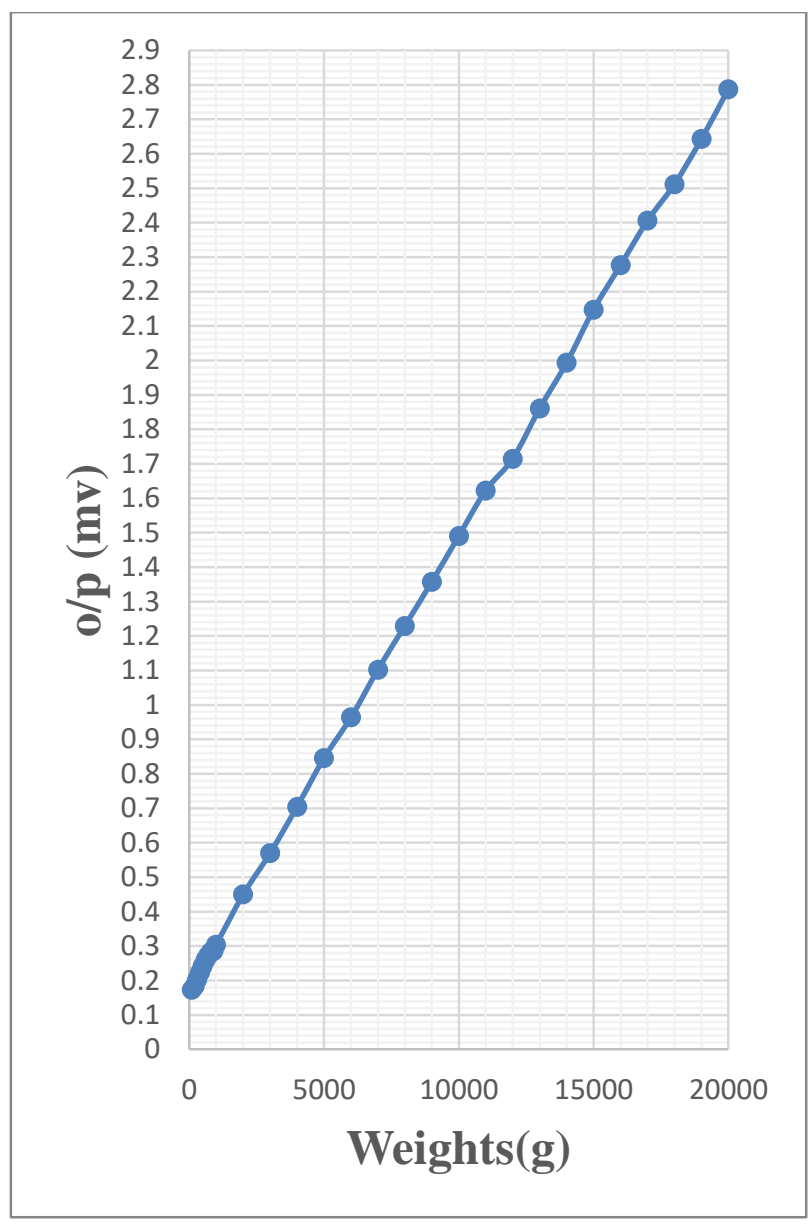

Figure(3). Load cell linearity.

After the linearity check of the used load cell all system is examined and its output is computed at different loads according to the flow chart given.

\subsection{The average function}

The average function will receive the readings and the number of readings and calculate the average for them and return the result to the main algorithm as shown in figure(4). 


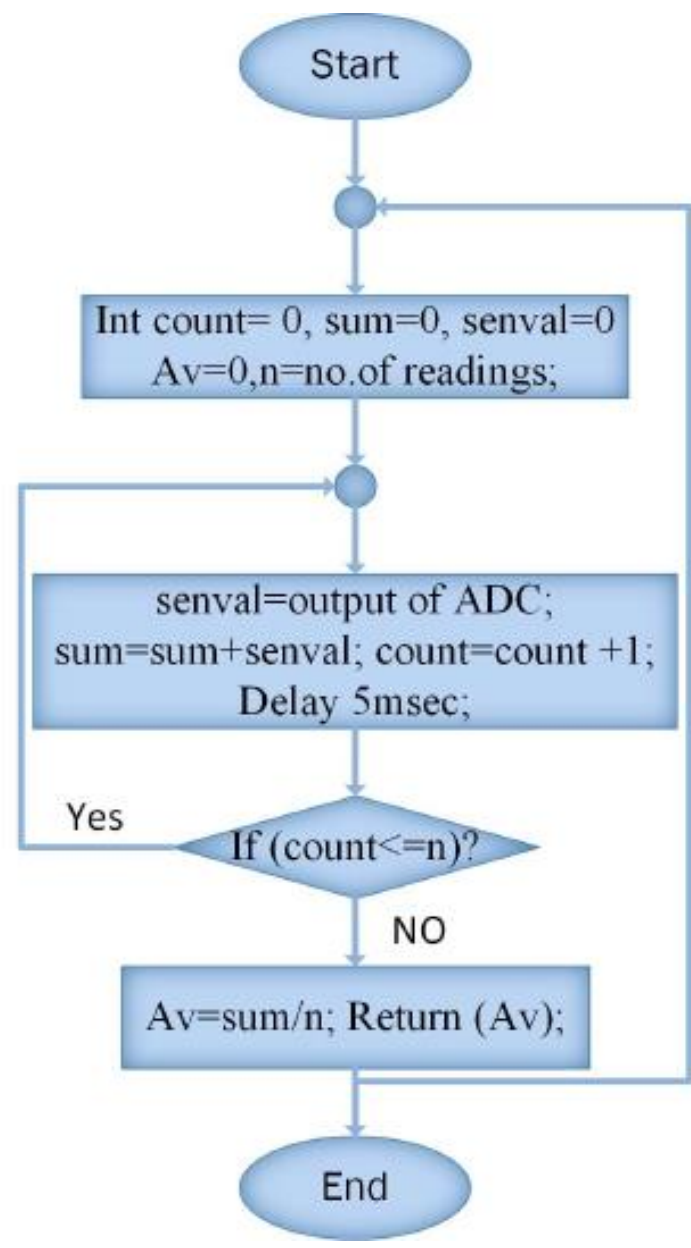

Figure(4). Average function flow chart.

\subsection{The window algorithm}

The window is introduced to excludes un wanted signals due to its high absolute error. It will call the average function to calculate the average for number of samples. The average is used to determine the limits of the window they are: The middle range, upper limit and lower limit. Then starts to read $n$ number of readings from the load cell at each reading determines if this reading lies within the boundaries of the window it is accepted otherwise, it is rejected. After that it will calculate the average for the readings after window, as well as, the average for readings before window as shown in figure(5).

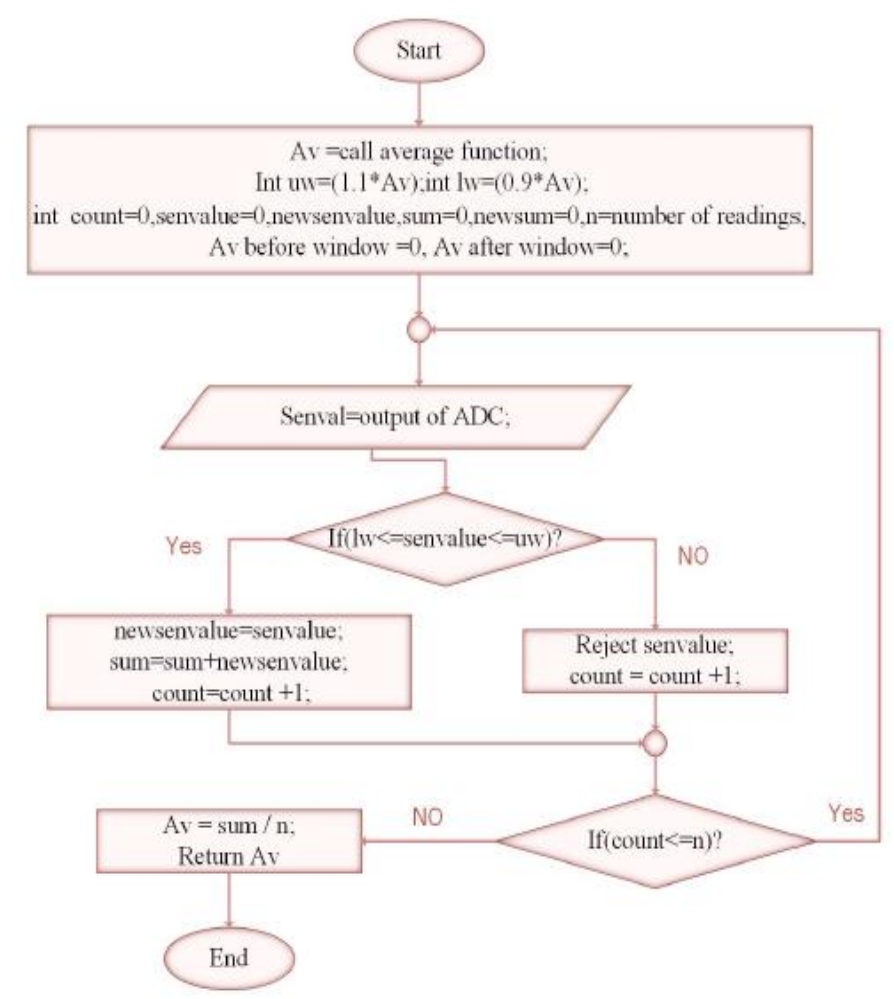

Figure(5). Window algorithm.

\subsection{Adaptive hardware gain.}

Three instrumentation amplifiers are used to build adaptive gain system as shown in figure (6) and figure(7). One amplifier output is activated according to the input signal range by the adaptive algorithm.

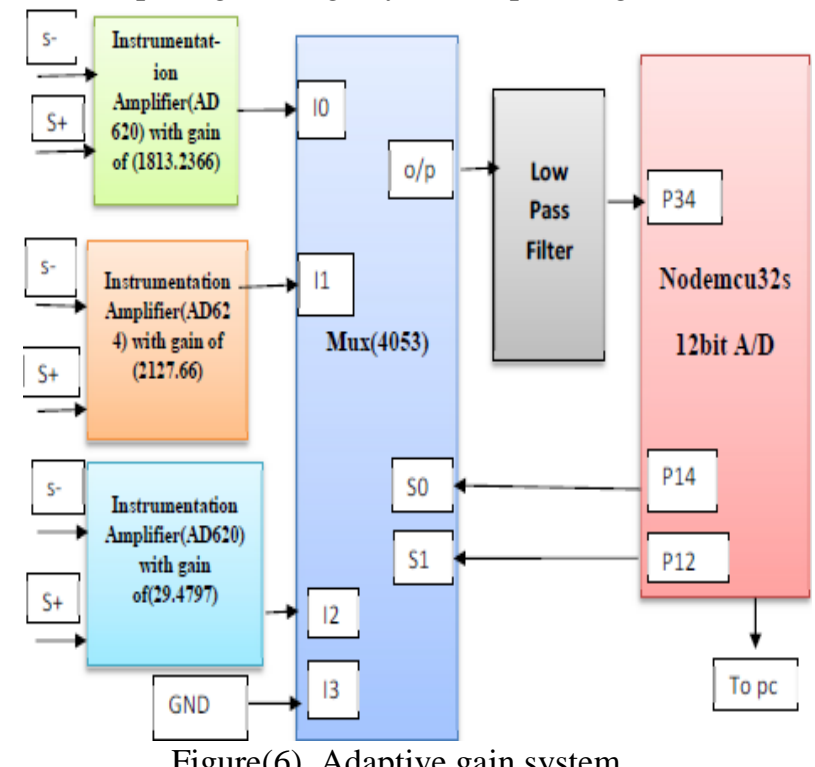

Figure(6). Adaptive gain system. 


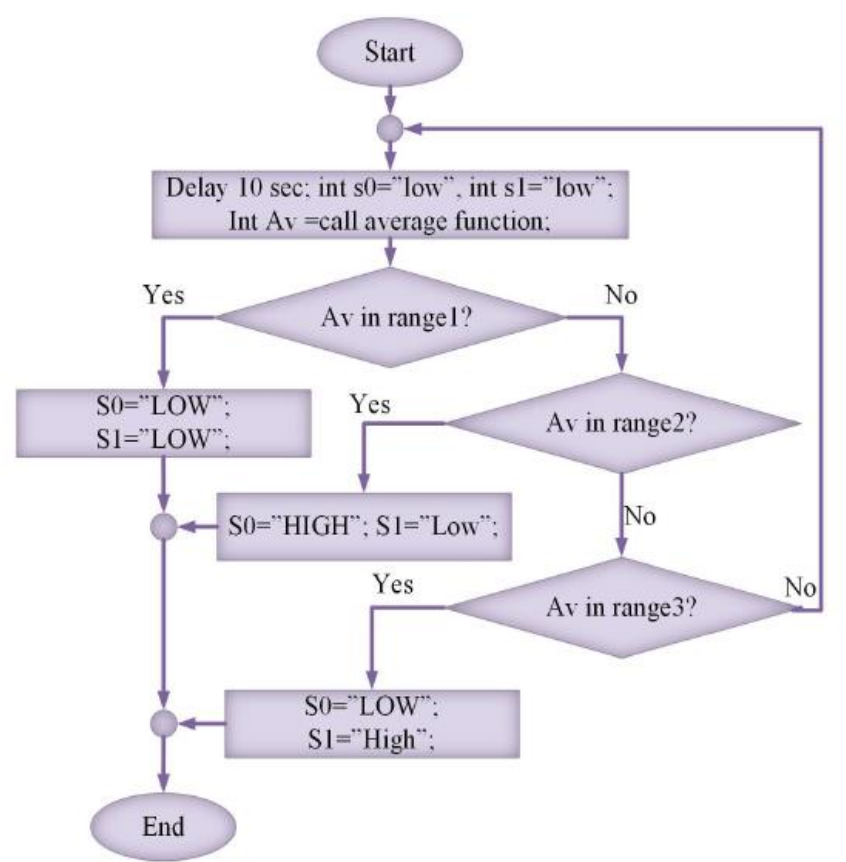

Figure(7). Adaptive gain algorithm.

\section{The results.}

\subsection{Window results}

The combined error is calculated which is $\pm 0.416 \%$ from the weight $6000 \mathrm{~g}$, the sigma improvement is $6.922 \%$ as shown in figures(8)and(9). Combined error $=\frac{\text { weight }(\text { measured })-\text { weight }(\text { true })}{\text { weight(true })}$

Sigma $=\sqrt{\frac{\sum(x-\bar{x})(x-\bar{x})}{n-1}}$

Where:

$x$ : reading value.

$\bar{x}$ : average of readings values.

$n$ : no. of readings.

Table 4.1: $6 \mathrm{~kg}$ by using the window

\begin{tabular}{|l|c|c|c|c|c|c|}
\hline & Average & Sigma & Weight(g) & $\begin{array}{c}\text { Combined } \\
\text { error }\end{array}$ & $\begin{array}{c}\text { Sigma } \\
\text { improvement\% }\end{array}$ & $\begin{array}{c}\text { no. of } \\
\text { readings }\end{array}$ \\
\hline Before window & 980.638 & 10.617 & 6025 & $\pm 0.416 \%$ & $\ldots-.$. & 100000 \\
\hline After window & 980.660 & 9.882 & 6025 & $\pm 0.416 \%$ & $6.922 \%$ & 100000 \\
\hline
\end{tabular}

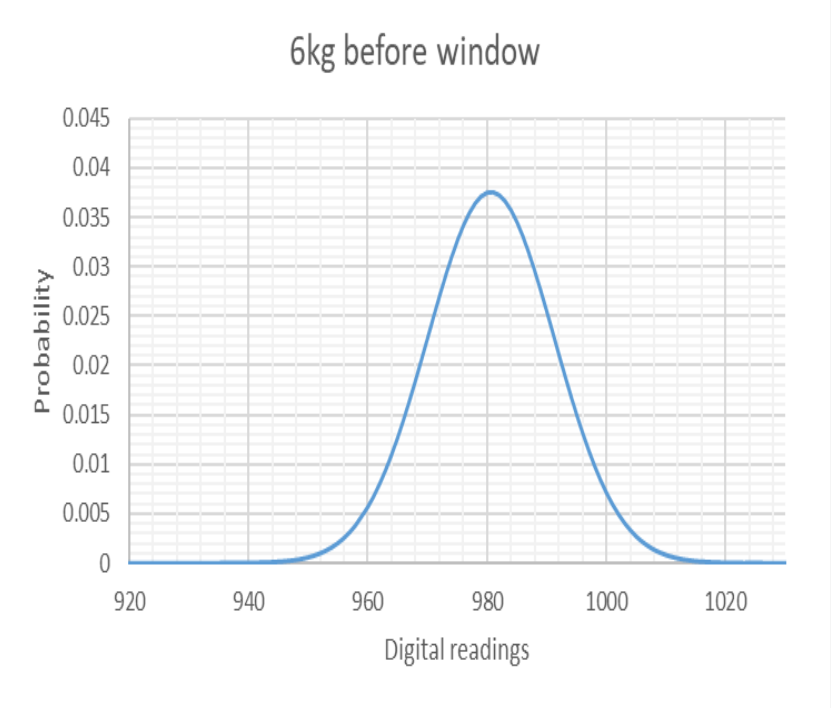

Figure(8). 6kg before window.

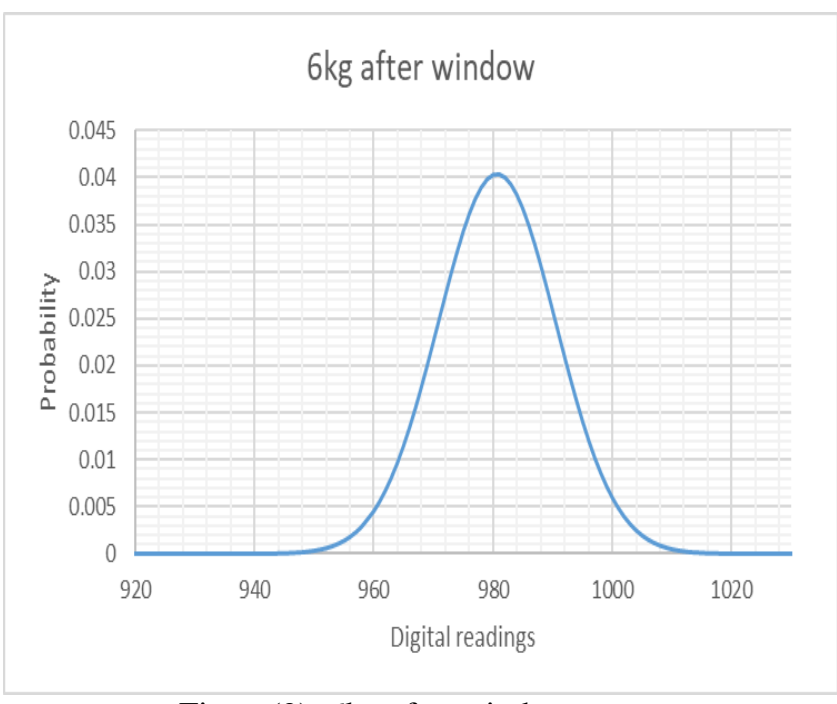

Figure(9). 6kg after window.

\subsection{Adaptive hardware gain.}

The combined error is calculated which is $\pm 0.008666 \%$ from the weight $5999.48 \mathrm{~g}$, sigma improvement is $0 \%$ as shown in figures(10) and (11).

Table 4.2: $6 \mathrm{~kg}$ by using adaptive gain.

\begin{tabular}{|c|c|c|c|c|c|c|}
\hline & Average & Sigma & Weight(g) & $\begin{array}{c}\text { Combined } \\
\text { enror }\end{array}$ & $\begin{array}{c}\text { Sigma } \\
\text { improvement\% \% }\end{array}$ & $\begin{array}{c}\text { no. of } \\
\text { readings }\end{array}$ \\
\hline $\begin{array}{c}\text { Before adaptive } \\
\text { gain }\end{array}$ & 2250.641 & 10.974 & 5999.48 & $=0.009 \%$ & $\ldots$ & 80000 \\
\hline $\begin{array}{c}\text { After adaptive } \\
\text { gain }\end{array}$ & 2250.641 & 10.974 & 5999.48 & $=0.009 \%$ & $0 \%$ & 80000 \\
\hline
\end{tabular}




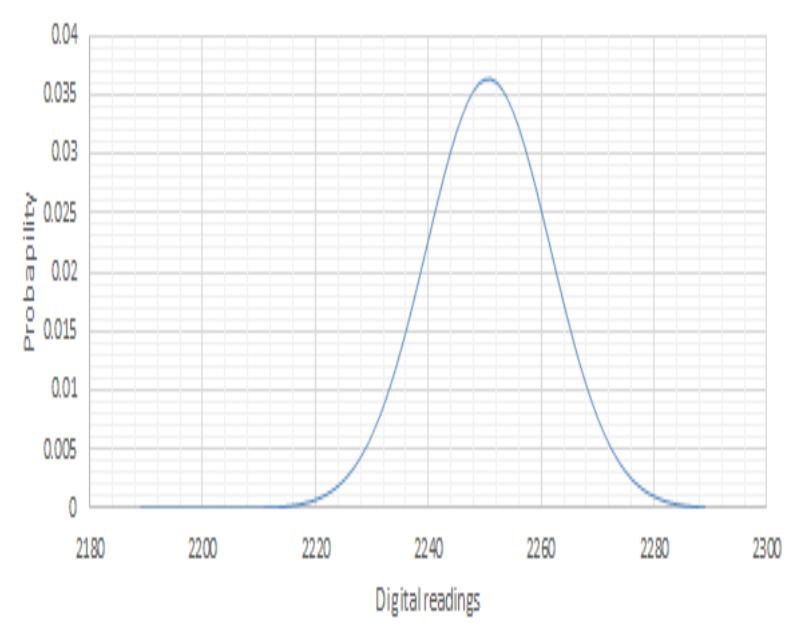

Figure(10). 6kg before adaptive gain.

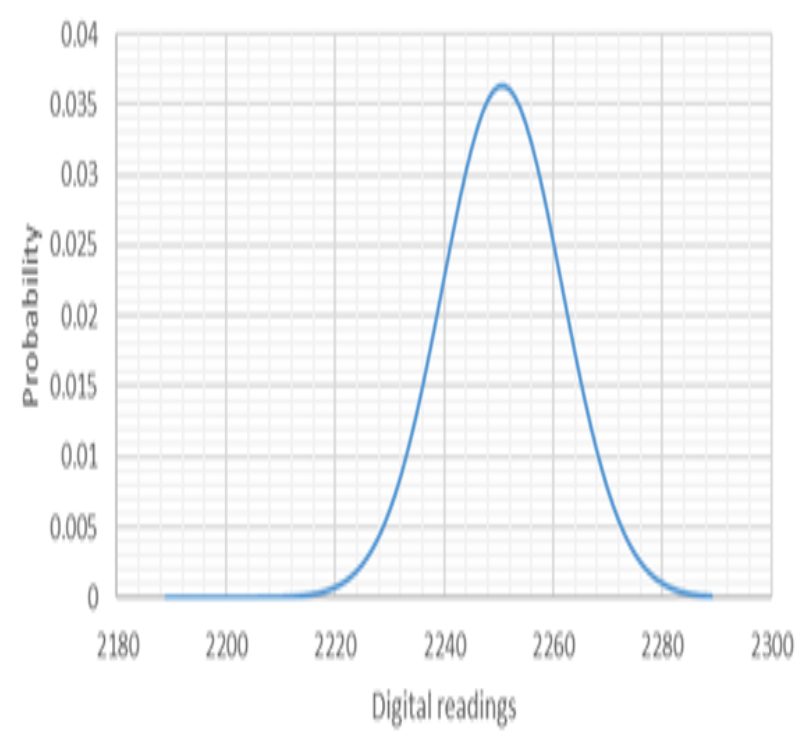

Figure(11). 6kg after adaptive gain.

\section{CONCLUSION}

The proposed approach is used to reduce the error in weighing signal. The algorithm computes the average of the load applied on the load cell. This paper discusses many software techniques to handle the error in weighing signal. The first, by using the window, in which the computed average is assigned in to one of three ranges: lower limit, middle limit and upper limit. The window parameter or width is practically found to be $\pm 0.1 \%$. As an example $6 \mathrm{~kg}$ is measured as $6025 \mathrm{~g}$. The combined error is calculated which is $\pm 0.416 \%$ from the weight $\mathrm{g}$, the sigma improvement is $6.922 \%$.The second, by using adaptive hardware gain for the same load the combined error was $\pm 0.008666 \%$ from the weight $5999.48 \mathrm{~g}$, sigma improvement is $0 \%$. However, the speed of measurement is improved by about $20 \%$. Therefore the second method which is adaptive gain is the best.

\section{REFERENCES}

[1] From the datasheet, "Load Cell and Weigh Module Handbook", Rice Lake Weighing Systems,,www.ricelake.com,800-472-6703, 2017.

[2] T. Kopczynski, "Five Factors That Can Affect Your Weighing System's Accuracy, Hardy Process Solutions" 9440 Carroll Park Drive • San Diego, CA 92121,2011.

[3] M.Kiavi, "Design and fabrication of a microcontroller based electronic weighing machine in high mass regime". Diss. MSc Thesis, Kenyatta University, 2009.

[4] K.Chatterjee, S. N.Mahato, \& S.Chattopadhyay, "Weighing System by Load Cell Response Rectification Method", International Journal of Measurement Technologies and Instrumentation Engineering (IJMTIE), 2(3), 34-44, 2012.

[5] N. C.Kyoo, Noise in Load Cell Signal in an "Automatic Weighing System Based on a Belt Conveyor", Journal of Sensors, Article ID 1524782, 9 pages ,2017.

[6] S.Pitawala, State estimation for dynamic weighing using Kalman filter. Diss. Victoria University of Wellington, 2019. 


\section{معالجة الخطأ في الإثارة الوزنية}

\author{
فخر الدين حامد علي \\ fhazaa@uomosul.edu.iq
}

عبدالقادر فارس عبدالقادر

abdlkaderfares52@gmail.com

جامعة الموصل ـ كلية الهنسة ـ قسم هنسة الحاسوب

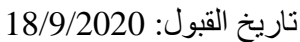

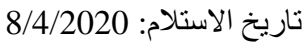

الملخص

يقدم البحث كيفية استخدام بعض تقنيات البرمجيات للتعامل مع الخطأ في إثارة الوزن التي يتم إنتاجها من خلية الحمل. خلية الحمل هي أفضل جهاز

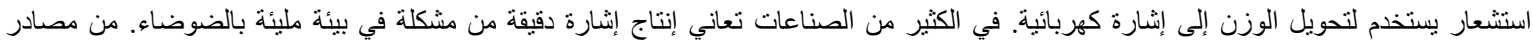

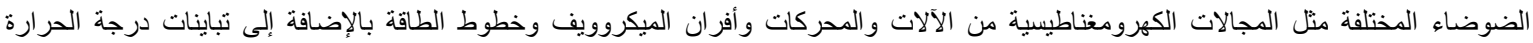

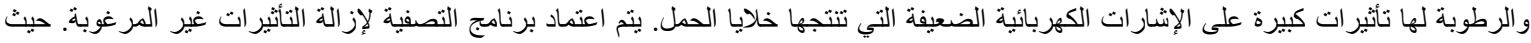

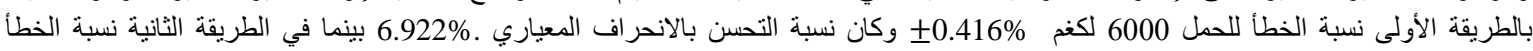
للحملم

(الكلمات الدالهه :

الاردوينو خلية الحمل، أداة التكبير ، محول الإشارة التناظرية الى رقمبية. 